REVISTA EVIDENCIAÇÃO CONTÁBIL \& FINANÇAS

João Pessoa, v. 4, n. 2, p. 68-81, maio/ago. 2016.

ISSN 2318-1001

DOI: 10.18405/recfin20160205

Disponível em: http://periodicos.ufpb.br/ojs2/index.php/recfin

\title{
NÍVEL DE SIMILARIDADE DOS CURRÍCULOS DOS CURSOS DE CIÊNCIAS CONTÁBEIS DE INSTITUIÇÕES CATARINENSES EM RELAÇÃO AO CURRÍCULO MUNDIAL PROPOSTO PELO ISAR/UNCTAD/ONU 1
}

\author{
SIMILARITY LEVEL OF THE CURRICULA IN ACCOUNTING COURSES OF \\ INSTITUTIONS FROM SANTA CATARINA STATE, BRAZIL, IN RELATION TO \\ THE WORLWIDE CURRICULUM PROPOSED BY ISAR/UNCTAD/UN
}

\author{
Luís Antônio Lay ${ }^{2}$ \\ Mestrando em Ciências Contábeis pela Universidade Regional de Blumenau (FURB) \\ luisantoniolay@gmail.com \\ Antônio Carlos Bambino \\ Mestrando em Ciências Contábeis pela FURB \\ julbam@terra.com.br \\ Thiago Bruno de Jesus Silva \\ Mestrando em Ciências Contábeis pela FURB \\ thiagobruno.silva@yahoo.com \\ Roberto Carlos Klann \\ Doutor em Ciências Contábeis e Administração pela FURB \\ Professor do Programa de Pós-Graduação em Ciências Contábeis da FURB \\ $\underline{\text { rklann@furb.br }}$
}

\section{RESUMO}

A influência da globalização nas economias locais, sobretudo de países emergentes, é evidente, por exemplo, nas leis nacionais como pré-requisito à desregulamentação, privatização e o incremento de padrões industriais e tecnológicos internacionais para vários setores da economia, entre eles a educação. O presente estudo teve como objetivo comparar a adequação das matrizes curriculares dos cursos de Ciências Contábeis em instituições de Santa Catarina com a matriz curricular proposta pela ONU/UNCTAD/ISAR. Para tal, adotou-se uma pesquisa descritiva, com análise documental, a partir de dados provenientes das matrizes curriculares das instituições de ensino da Associação Catarinense das Fundações Educacionais (ACAFE). A abordagem utilizada no estudo referente ao problema foi qualitativa, sendo utilizado da análise de conteúdo para se ter os conteúdos presentes nas matrizes. Como resultados, constatou-se que das 16 instituições, 7 delas apresentaram um aumento nas áreas de conhecimentos contábeis, financeiros e assuntos afins. Sendo que as subáreas de políticas empresariais, de estruturas organizacionais básicas e comportamento estão sendo as mais abordadas. No entanto, em relação aos métodos quantitativos e estatísticos, estes são os que mais estão

\footnotetext{
${ }^{1}$ Artigo recebido em: 29/02/2016. Revisado por pares em: 22/06/2016. Versão final recebida em: 24/07/2016. Recomendado para publicação em: 01/08/2016 por Luiz Felipe de Araújo Pontes Girão (Editor Adjunto). Publicado em: 30/08/2016. Organização responsável pelo periódico: UFPB.

2 Endereço: Rua Antônio da Veiga, 140, CEP 89.012-900, Blumenau/SC.

DOI: http://dx.doi.org/10.18405/recfin20160205
} 
presentes nas matrizes curriculares das instituições. Pode-se concluir que as instituições do estudo estão mais próximas de uma congruência de seu currículo com o proposto pela ONU/UNCTAD/ISAR, e que há um crescimento nas áreas de Conhecimentos Contábeis, Financeiros e assuntos afins e Conhecimento (avançado) em Contabilidade, Finanças e assuntos afins. Em relação a estudos futuros, é oportuno avaliar as ementas dessas disciplinas, para verificar se estas estão alinhadas com as disciplinas sugeridas pelo Currículo Mundial.

Palavras-chave: Currículo Internacional; Ciências Contábeis; Educação Contábil; Harmonização Contábil.

\section{ABSTRACT}

The influence of globalization on local economies, mainly on emerging countries, is evident, for instance, in the national laws as pre-requisite for deregulation, privatization and increase of international industrial and technological standards for several economic sectors, as education. The present study aimed at comparing the curricula adjustment of accounting courses with the curriculum proposed by UN/UNCTAD/ISAR. To reach such a goal, a descriptive study with documental analysis was implemented. Data was collected from the curricula of educational institutions affiliated to ACAFE, which stands for the Association of Educational Foundations of the Santa Catarina state. Content analysis of qualitative nature was conducted to address the problem. Findings indicate that from the 16 institutions from which the curricula were collected, 7 institutions present an increase in the areas of accounting and financial knowledge as well as related topics. The subareas of corporate policies, basic organizational structures and behavior are the ones that receive most attention. Notwithstanding, the quantitative and statistical methods are still the most focused ones in the curricula of such institutions. Such results lead to the conclusion that the institutions are closer to being congruent with the curriculum proposed by UN/UNCTAD/ISAR. There seems to be an increase in the areas of accounting and financial knowledge and related topics as well as in advanced knowledge in accounting, finance and associated topics. As suggestions for further research, it is advisable to evaluate the syllabi of such courses to verify whether they are aligned with the courses suggested by the international curriculum.

Keywords: International Curriculum; Accounting; Accounting Education; Accounting Standardization.

\section{INTRODUÇÃO}

Sob a influência da globalização, nas economias locais, sobretudo de países emergentes, têm passado por diversas mudanças, como por exemplo: as leis nacionais como pré-requisito à desregulamentação, privatização e o incremento de padrões industriais e tecnológicos internacionais para vários setores da economia, entre eles a educação. Santos et al. (2013) afirmam que a política econômica e social local, peculiares de cada país, podem resultar na diversidade de interpretações dos fenômenos contábeis de um país para o outro, deste modo, verifica-se que a contabilidade é diferente de um país para o outro. Nesse sentido, Niyama (2005) comenta que os sistemas contábeis dos países são influenciados por um conjunto de regras próprias, como leis, filosofias, procedimentos e objetivos. Que de certa forma provem da educação aplicada.

Riccio e Sakata (2004) apresentam que a contabilidade permeia as sociedades nos diversos países. O seu caráter regulatório e padronizador tem sido destacado ainda mais pela globalização, como elemento fundamental para o controle e avaliação do desempenho das instituições públicas e privadas. Nesse contexto surgiram as Normas Internacionais de Contabilidade, com a intenção de harmonizar, convergir os padrões contábeis em uma única linguagem de negócio universal (ERFURTH; DOMINGUES, 2013). 
No campo educacional, os países, norteados por suas políticas econômicas e sociais, aplicam diferentes metodologias e abordagens no ensino da contabilidade. Desta forma, as instituições de educação formam profissionais com habilidades e competências próximas àquelas exigidas pelo mercado local. Santos et al. (2013) entendem que a diversidade curricular no ensino da contabilidade pode não contribuir para a consolidação do ensino contábil. Segundo Segantini et al. (2013), devido ao processo de harmonização e convergência internacional às Normas Internacionais de Contabilidade (NIC) editadas pelo International Accounting Standards Board (IASB), tem-se discutido a possibilidade de um ensino uniforme para os cursos de Ciências Contábeis, o que passaria, obrigatoriamente, pela discussão de um currículo mínimo para todos os países participantes do processo de convergência.

As instituições educacionais estrangeiras e brasileiras iniciaram um processo de adaptação às pressões da globalização por meio da internacionalização dos currículos e de atividades. Este processo foi incentivado para minimizar a disparidade do ensino da contabilidade no mundo. A Organização das Nações Unidas (ONU), por meio do Intergovernmental Working Group of Experts on International Standards of Accounting and Reporting (ISAR), vinculado à United Nations Conference on Trade and Development (UNCTAD), desenvolveu uma sugestão de currículo para que os cursos superiores de Ciências Contábeis possam basear a sua matriz curricular, com o intuito de que os bacharéis possuam formação com os conhecimentos semelhantes, necessários para a profissão, independentemente do país de origem (SEGANTINI et al., 2013).

Erfurth e Domingues (2008) afirmam que quanto maior for a similaridade entre as matrizes curriculares adotadas pelo país e as matrizes curriculares internacionais, maior será a evidência de harmonização na educação. A finalidade do desenvolvimento dessa matriz curricular internacional é facilitar a adaptação das Instituições de Ensino Superior (IES) em Ciências Contábeis dos países em desenvolvimento às Normas Internacionais de Contabilidade (ERFURTH; DOMINGUES, 2013).

No Brasil, as IES têm autonomia para elaborar seus currículos, devendo, porém, obedecer à regulamentação do Ministério da Educação (MEC). Os cursos de Ciências Contábeis devem estar de acordo com esta legislação, o que ocorre por meio da Resolução no 10/2004 do Conselho Nacional de Educação (CNE) e Câmara de Educação Superior (CES). Esta norma determina que a organização do curso de graduação em Ciências Contábeis deve ser promovida por meio de um projeto pedagógico que venha a contemplar uma série de requisitos básicos para a formação do contador (BRASIL, 2004).

A educação formal dos profissionais de contabilidade, no mundo, deve convergir para os mesmos conjuntos de conhecimentos, harmonizados e globalizados, com exceção ao conjunto de conhecimentos específicos de cada país, como história e cultura (RICCIO; SAKATA, 2004). A questão é que o ensino de Ciências Contábeis se limita com frequência às normas e a seus próprios procedimentos de adoção de normas, constituindo um importante obstáculo para a integração da economia global. O objetivo do currículo mundial proposto pela ONU/UNCTAD/ISAR não é estabelecer uma qualificação mundial, no entanto, servir de modelo, guia, qualificação mínima, regulamento voluntário, referência e base para harmonização, com o intuito de fortalecer a profissão contábil para oferecer seus serviços além das fronteiras nacionais (ERFURTH; DOMINGUES, 2013).

Assim, diversos estudos têm se dedicado a estudar a similaridade das matrizes curriculares dos cursos de Ciências Contábeis, como Riccio e Sakata (2004), Erfurth e Domingues (2008, 2013), Czesnat, Cunha e Domingues (2009), Santos et al. (2013), Cavalcanti (2013) e Segantini et al. (2013). No entanto, percebe-se uma lacuna em se tratando dos cursos de Ciências Contábeis do Estado de Santa Catarina/Brasil. Embora Czesnat, Cunha e Domingues (2009) pesquisaram os currículos de Ciências Contábeis das Universidades do Estado de Santa Catarina listadas pelo MEC e compararam com o currículo mundial, os autores mencionaram nos seus achados que apenas quatro das 11 universidades pesquisadas apresentam a disciplina Contabilidade Internacional como obrigatórias em 
seus currículos. Vale ressaltar também que, neste período, foram pesquisadas 12 universidades e, atualmente, há 16 IES associadas ao Sistema ACAFE.

Diante desse contexto, este estudo apresenta o seguinte problema de pesquisa: as disciplinas oferecidas nas grades curriculares das IES vinculadas ao Sistema ACAFE possuem similaridades com àquelas previstas na matriz curricular proposta pela ONU/UNCTAD/ISAR? Desta forma, o estudo tem o objetivo de comparar a adequação das matrizes curriculares dos cursos de Ciências Contábeis com a matriz curricular proposta pela ONU/UNCTAD/ISAR, sendo que os estudos anteriores já têm 3 anos de publicação, e que nesse meio acadêmico já pode ter ocorrido mudanças pelos resultados encontrados no período.

Os resultados deste estudo podem auxiliar as IES componentes da amostra a reorganizarem suas matrizes curriculares, no sentido de melhor harmonizá-las com a grade internacional proposta pela ONU/UNCTAD/ISAR, visto que os estudos anteriores apresentam uma distância dos dias atuais, o que leva a crer que possam ter ocorridas mudança nos currículos. Além disso, acredita-se que esses resultados possam ajudar outras IES do país que estejam procurando adaptar suas matrizes curriculares à proposta internacional.

\section{REFERENCIAL TEÓRICO}

Este capítulo aborda a proposta de um currículo mundial para os cursos de Ciências Contábeis, oriunda da ONU/UNCTAD/ISAR, bem como estudos relacionados a essa temática. A intenção das normas, conforme exposto, seria minimizar as diferenças e divergências em função de cada país possuir o seu sistema particular de contabilidade

\subsection{Proposta de Currículo Mundial da ONU/UNCTAC/ISAR}

A Organização das Nações Unidas (ONU), por meio do Intergovernmental Working Group of Experts on International Standards of Accounting and Reporting (ISAR), vinculado à United Nations Conference on Trade and Development (UNCTAD), desenvolveu um currículo para servir como guia na formulação das matrizes curriculares dos cursos superiores em Ciências Contábeis de todo o mundo (UNCTAD, 1999). O intuito do desenvolvimento desse currículo foi apresentar para a comunidade internacional as principais disciplinas técnicas que um indivíduo deveria saber para se tornar um profissional contábil (UNCTAD, 2009).

Czesnat, Cunha e Domingues (2009) argumentam a importância de que os conhecimentos dos profissionais contábeis tenham sintonia com as normas contábeis internacionais, estando apto para administrá-las, explicá-las e aplicá-las conforme sua necessidade. Assim, a harmonização dos currículos versa na possibilidade de diminuir as lacunas nos sistemas nacionais de formação, reduzir os custos de mútuos acordos de reconhecimento e aumentar o comércio internacional de serviços contábeis (UNCTAD, 2009).

Os blocos de conhecimentos foram definidos pelo ISAR/UNCTAD na $20^{\mathrm{a}}$ reunião da UNCTAD, realizada em 2003, sendo que foi adotado o documento TD/B/COM.2/ISAR/21 com o qual se introduziu modificações nas diretrizes curriculares propostas no TD/B/COM.2/ISAR/6. Por conseguinte, apresenta-se o TD/B/COM.2/ISAR/21 detalhado no Quadro 1.

O Quadro 1 apresenta os 4 blocos de conhecimento que compõem as disciplinas propostas pelo ISAR/UNCTAD para o Currículo Mundial, divididos em 23 módulos com disciplinas específicas para cada módulo (UNCTAD, 2009). Magalhães e Andrade (2006) ressaltam que o Currículo Mundial é um ponto inicial para aqueles países que desejam harmonizar o seu sistema de ensino com os outros países. Destaca-se que a ONU/UNCTAD/ISAR, ao produzir os TD/B/COM.2/ISAR/5, TD/B/COM.2/ISAR/6 e TD/B/COM.2/ISAR/21, objetivou preparar um programa mundial que servisse de referência para o ensino da Contabilidade, auxiliando na redução de tempo e de custos de negociações para os reportes mútuos na área contábil (UNCTAD, 2009). 
Quadro 1 - Bloco de Conhecimento definidos pelo ISAR/UNCTAD.

\begin{tabular}{|c|c|c|c|}
\hline $\begin{array}{l}\text { 1- Conhecimento Admi- } \\
\text { nistrativo e Organizacio- } \\
\text { nal }\end{array}$ & $\begin{array}{l}2 \text { - Tecnologia de Infor- } \\
\text { mação }\end{array}$ & $\begin{array}{l}\text { 3- Conhecimento Contá- } \\
\text { beis, Financeiros e As- } \\
\text { suntos Afins }\end{array}$ & $\begin{array}{l}\text { 4- Conhecimento (avançado) } \\
\text { em Contabilidade, Finanças e } \\
\text { Assuntos Afins }\end{array}$ \\
\hline $\begin{array}{l}\text { a) Economia; } \\
\text { b) Métodos quantitativos } \\
\text { e estatísticos para as em- } \\
\text { presas; } \\
\text { c) Politicas empresariais, } \\
\text { de estrutura organizacio- } \\
\text { nais básicas, e comporta- } \\
\text { mento organizacional; } \\
\text { d) Funções e práticas ad- } \\
\text { ministrativas, e gestão de } \\
\text { operações; } \\
\text { e) Marketing; } \\
\text { f) Mercados internacio- } \\
\text { nais. }\end{array}$ & $\begin{array}{l}\text { a) Tecnologia de informa- } \\
\text { ção. }\end{array}$ & $\begin{array}{l}\text { a) Contabilidade básica; } \\
\text { b) Contabilidade finan- } \\
\text { ceira; } \\
\text { c) Contabilidade finan- } \\
\text { ceira avançada; } \\
\text { d) Contabilidade gerencial } \\
\text { (conceitos básicos); } \\
\text { e) Tributação; } \\
\text { f) Sistemas de informações } \\
\text { contábeis; } \\
\text { g) Direto comercial e em- } \\
\text { presarial; } \\
\text { h) Fundamentos sobre au- } \\
\text { ditoria; } \\
\text { i) Finanças empresariais e } \\
\text { gestão financeira; } \\
\text { j) Módulo sobre integra- } \\
\text { ção do conhecimento: a } \\
\text { capstone. }\end{array}$ & $\begin{array}{l}\text { a) Demonstrações financeiras } \\
\text { avançadas e contabilidade in- } \\
\text { dustrial; } \\
\text { b) Contabilidade gerencial } \\
\text { avançada; } \\
\text { c) Tributação avançada; } \\
\text { d) Direito empresarial avan- } \\
\text { çado; } \\
\text { e) Auditoria avançada } \\
\text { Finanças empresariais avança- } \\
\text { das e administração financeira; } \\
\text { f) Estágio contábil. }\end{array}$ \\
\hline
\end{tabular}

Fonte: Adaptado de UNCTAD (2009).

O Currículo Referência ou Currículo Mundial é composto de duas categorias: a primeira, TD/B/COM.2/ISAR/5, é um guia para sistemas nacionais de qualificação de contadores; a segunda, TD/B/COM.2/ISAR/6, é composta por um conjunto de áreas do conhecimento necessárias para a educação profissional dos contadores. Assim, o modelo de plano de estudos publicado pelo TD/B/COM.2/ISAR/6 em 1999 foi revisado em 2003 com o documento Revised Model Accounting Curriculum (MC), o qual descreve de forma detalhada os conteúdos de cada um dos blocos de conhecimento (ERFURTH; DOMINGUES, 2008).

A proposta principal desse documento, segundo Czesnat, Cunha e Domingues (2009), é servir como base para as instituições de ensino superior formularem os seus currículos, buscando uma uniformização dos estudos de Contabilidade, ou seja, a ISAR propôs uma estrutura curricular mundial para orientar as instituições de ensino superior a desenvolver planos de estudos semelhantes, favorecendo um ensino em Contabilidade em âmbito mundial.

Conforme UNCTAD/ISAR (2003) o currículo teve seu surgimento com a finalidade de regular a comunidade internacional sobre os assuntos que um ano de uma IES necessite para que se torne um profissional na área de contabilidade. Desta forma, os autores Riccio e Sakata (2004) destacam que a proposta que a UNCTAD de um currículo com temas a serem abordados, tende a ser o mínimo de um IES abordar em seu currículo. E que segundo a UNCTAD (2009), o currículo apresentado por eles, tem como objetivo de criar um ponto de referência para uma qualificação da profissão de contabilidade, o que reflete em um melhor profissional para um mercado globalizado.

\subsection{Estudos Relacionados}

Diversos estudos têm sido desenvolvidos sobre a convergência das matrizes curriculares dos cursos de Ciências Contábeis ao modelo proposto pela ONU/UNCTAD/ISAR, podendo-se citar os de Riccio e Sakata (2004), Erfurth e Domingues (2008, 2013), Czesnat, Cunha e Domingues (2009), Santos et al. (2013), Cavalcanti (2013) e Segantini et al. (2013).

Riccio e Sakata (2004) pesquisaram as evidências da globalização na educação contábil. A população do estudo foi formada por 142 universidades no Brasil e 60 universidades e Institutos em 
Portugal. A amostra compreendeu 25 cursos de Contabilidade em universidades e faculdades do Brasil e 25 cursos de Contabilidade ou área relacionada em universidades e instituições de ensino de Portugal. No geral, os resultados do estudo apontam que as universidades brasileiras estão mais próximas do modelo internacional do que as portuguesas. Algumas universidades/instituições, em particular, mostraram-se muito afastadas do modelo do ISAR/UNCTAD.

Os autores perceberam que o Bloco de Conhecimentos Administrativos e Organizacionais, tanto no Brasil como em Portugal, foi o que apresentou maior aproximação. O que mais se distanciou foi o bloco de Conhecimentos Gerais. Outra característica notada nos resultados foi a baixa quantidade de disciplinas de Tecnologia de Informação presente na maioria das matrizes curriculares. Foram encontradas 27 disciplinas de línguas estrangeiras nas universidades portuguesas, como Inglês e Francês, o que pode representar indícios da globalização refletindo provavelmente o resultado da União Europeia. Uma evidência esperada da globalização do currículo contábil, segundo os autores, seria a presença de disciplinas relacionadas a assuntos internacionais. De um total de 1.906 disciplinas obrigatórias na América do Sul, apenas três referiam-se à Contabilidade Internacional, dez a Negócios Internacionais e uma à Economia Internacional.

Erfurth e Domingues $(2008,2013)$ analisaram as similaridades e as diferenças das matrizes curriculares de cursos de graduação em Ciências Contábeis no Brasil e na Argentina à luz do currículo mundial (CM) proposto pela ONU/UNCTAD/ISAR. Os resultados encontrados mostram que no Brasil existe maior similaridade nas áreas de conhecimento sobre gestão e administração das atividades, contabilidade gerencial, contabilidade básica e estágio. Na Argentina os conteúdos sobre economia, contabilidade financeira, contabilidade do nível avançado para indústrias especializadas e contabilidade tributária avançada foram as que mostraram similaridade com o currículo mundial.

Czesnat, Cunha e Domingues (2009) analisaram as matrizes curriculares dos cursos de Ciências Contábeis das Universidades do Estado de Santa Catarina listadas pelo MEC e compararam com o currículo mundial proposto pela ONU/UNCTAD/ISAR. A pesquisa demonstrou que os currículos dos cursos pesquisados possuem alta similaridade com o currículo mundial, alcançando um índice de $88,27 \%$, com foco em geral no mercado. Os autores ressaltaram nos seus achados que apenas quatro das 11 universidades pesquisadas apresentaram a disciplina Contabilidade Internacional como obrigatórias em suas matrizes curriculares.

Cavalcanti (2013) objetivou verificar o nível de adequação das matrizes curriculares dos cursos de Ciências Contábeis das IES goianas ao modelo de currículo mundial. Por meio de uma pesquisa descritiva, fundamentada em material documental-bibliográfico e de abordagem qualitativa, foram selecionados os currículos de 20 IES que oferecem a graduação em Ciências Contábeis no Estado de Goiás. Os resultados revelaram, dentre outros fatores, que os currículos das IES pesquisadas apresentaram $43 \%$ de similaridade com a proposta de currículo mundial da ONU/UNCTAD/ISAR.

Segantini et al. (2013) compararam a adequação das matrizes curriculares dos cursos de Ciências Contábeis de quatro universidades do Mercosul com o currículo proposto pela ONU/UNCTAD/ISAR. Os resultados indicaram que a similaridade entre os currículos das quatro universidades selecionadas com o proposto pela ONU/UNCTAD/ISAR é alta, existindo, em média, 76,7\% de semelhança entre as disciplinas que compõem as matrizes curriculares. Por ser apenas uma recomendação, as universidades pesquisadas demonstraram possuir certa flexibilidade na elaboração de seus currículos.

Santos et al. (2013) pesquisaram o nível de similaridade das matrizes curriculares dos cursos de Ciências Contábeis das instituições paranaenses e concluíram que elas apresentam 88,38\% de similaridade com o currículo mundial. Ao analisar os blocos individuais, verificaram um desequilíbrio de similaridade. Por exemplo, o bloco Tecnologia da Informação apresentou baixo índice de 
similaridade $(2,06 \%)$ ao currículo mundial, o que pode predizer um fraco desempenho dos profissionais contadores nas questões que remetam aos aspectos tecnológicos. De modo geral, a pesquisa mostrou que as matrizes curriculares das Instituições de Ensino do Estado do Paraná estão alinhadas às recomendações do currículo mundial quanto às disciplinas a serem oferecidas.

\section{PROCEDIMENTOS METODOLÓGICOS}

Para comparar a adequação das matrizes curriculares dos cursos de Ciências Contábeis com o currículo mundial proposto pela ONU/UNCTAD/ISAR, adotou-se uma pesquisa descritiva, com análise documental, a partir de dados provenientes das matrizes curriculares das instituições de ensino. A abordagem foi qualitativa, com a utilização de análise de conteúdo para responder à questão de pesquisa. A população e a amostra da pesquisa foram compostas pelas 16 instituições de ensino filiadas à Associação Catarinense das Fundações Educacionais (ACAFE), a qual foi criada em 1974, a partir da iniciativa dos dirigentes das próprias fundações, como instituição responsável pela consolidação do processo de organização, expansão e interiorização do ensino superior fundacional,

Em síntese, o ensino superior no Estado de Santa Catarina foi desenvolvido com base em um modelo diferente do presente em outras unidades da federação. Com a presença de uma única universidade federal, foram criadas por alguns municípios catarinenses fundações educacionais estabelecidas por leis municipais. São entidades públicas sem fins lucrativos, mas de direito privado, ou seja, embora tenham sua origem como entidades públicas, não recebem nenhuma subvenção do poder público e sobrevivem com a cobrança de mensalidade de seus alunos (KLANN et al., 2012).

A escolha pelas instituições da ACAFE se deu em função da pesquisa de Czesnat, Cunha e Domingues (2009), os quais mencionaram nos seus achados que apenas quatro das 11 universidades pesquisadas apresentavam a disciplina Contabilidade Internacional como obrigatória em suas matrizes curriculares. Vale ressaltar também que atualmente o Sistema ACAFE conta com 16 IES filiadas, as quais estão apresentadas no Quadro 2.

Quadro 2 - População e amostra do estudo.

\begin{tabular}{|l|l|}
\hline \multicolumn{1}{|c|}{ Instituições } & \multicolumn{1}{|c|}{ Nomenclatura } \\
\hline Católica de Santa Catarina & CATÓLICA SC \\
Centro Universitário Barriga Verde & UNIBAVE \\
Centro Universitário Municipal de São José & USJ \\
Centro Universitário para o Desenvolvimento do Alto Vale do Itajaí & UNIDAVI \\
Universidade Comunitária da Região de Chapecó & UNOCHAPECÓ \\
Universidade da Região de Joinville & UNIVILLE \\
Universidade do Alto Vale do Rio do Peixe & UNIARP \\
Universidade do Contestado & UnC \\
Universidade do Estado de Santa Catarina & UDESC \\
Universidade do Extremo Sul Catarinense & UNESC \\
Universidade do Oeste de Santa Catarina & UNOESC \\
Universidade do Planalto Catarinense & UNIPLAC \\
Universidade do Sul de Santa Catarina & UNISUL \\
Universidade do Vale do Itajaí & UNIVALI \\
Universidade Regional de Blumenau & FURB \\
Centro Universitário de Brusque & UNIFEBE \\
\hline
\end{tabular}

Fonte: dados da pesquisa.

Definida a amostra do estudo, partiu-se para a coleta de dados nos portais eletrônicos das IES pesquisadas, bem como no site da UNCTAC em relação à composição do Currículo Mundial e suas áreas de conhecimento. A coleta de dados foi realizada no período de novembro a dezembro de 2014. A análise dos dados foi realizada pela comparação entre as disciplinas que compõem as matrizes curriculares das universidades pertencentes à amostra, com àquelas sugeridas no Currículo 
Mundial. A análise se deu em função da similaridade ou proximidade entre os nomes dados às disciplinas e em relação ao conteúdo das ementas.

As limitações sobre a forma de coleta das informações podem ter influência sobre os resultados encontrados, no entanto, para comparar se as IES estão em consonância com a matriz curricular proposta pela ONU/UNCTAD/ISAR, a forma que se procedeu a pesquisa não tira o seu grau de importância.

\section{ANÁLISE E DISCUSSÃO DOS RESULTADOS}

A Tabela 1 apresenta a relação das matrizes curriculares das instituições pesquisadas com relação ao Currículo Mundial proposto pela ONU/UNCTAD/ISAR.

Tabela 1 - Similaridades entre os currículos das IES com o currículo mundial.

\begin{tabular}{|c|c|c|c|c|c|c|c|}
\hline Instituição & 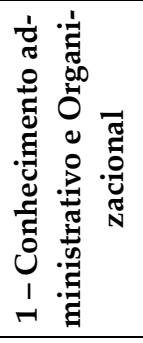 & 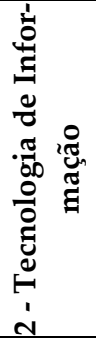 & 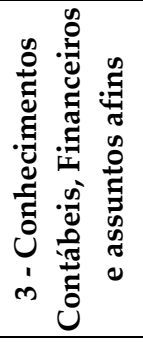 & 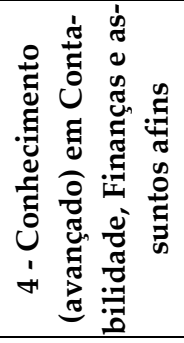 & 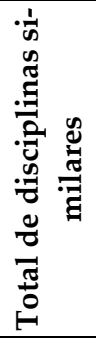 & 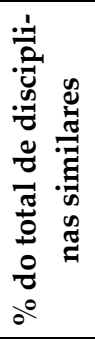 & 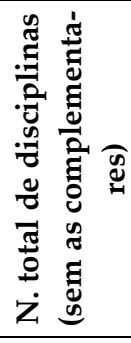 \\
\hline CATÓLICA SC & 6 & 0 & 13 & 10 & 29 & 80,1 & 36 \\
\hline FURB & 8 & 0 & 17 & 13 & 38 & 79,2 & 48 \\
\hline UDESC & 7 & 0 & 16 & 6 & 29 & 82,8 & 35 \\
\hline UnC & 6 & 0 & 14 & 10 & 30 & 73,2 & 41 \\
\hline UNESC & 5 & 0 & 16 & 13 & 34 & 75,6 & 45 \\
\hline UNIARP & 6 & 0 & 13 & 10 & 29 & 72,5 & 40 \\
\hline UNIBAVE & 8 & 1 & 15 & 6 & 30 & 75 & 40 \\
\hline UNIDAVI & 6 & 0 & 16 & 10 & 32 & 71,1 & 45 \\
\hline UNIFEBE & 7 & 0 & 16 & 6 & 29 & 64,4 & 45 \\
\hline UNIPLAC & 7 & 0 & 22 & 12 & 41 & 82 & 50 \\
\hline UNISUL & 6 & 0 & 15 & 9 & 30 & 71,4 & 42 \\
\hline UNIVALI & 5 & 0 & 15 & 10 & 30 & 76,9 & 39 \\
\hline UNIVILLE & 5 & 0 & 13 & 6 & 24 & 72,7 & 33 \\
\hline UNOCHAP & 5 & 0 & 15 & 12 & 32 & 71,1 & 45 \\
\hline UNOESC & 6 & 0 & 16 & 9 & 31 & 81,6 & 38 \\
\hline USJ & 9 & 1 & 12 & 8 & 30 & 83,3 & 36 \\
\hline Total & 102 & 2 & 244 & 150 & 498 & 75,7 & 658 \\
\hline
\end{tabular}

Fonte: Dados da pesquisa.

De acordo com a pesquisa, as IES integrantes da ACAFE tem em média 74,5\% das disciplinas de forma similar aos similares com o Currículo Mundial (ONU/UNCTAD/ISAR). Os destaques em percentuais são a USJ (com 83,3\%), a UNIPLAC (82\%) e a UNOESC (81,6\%). As matrizes curriculares que se apresentaram mais distantes da proposta pela ONU/UNCTAD/ISAR foram as da UNIFEBE e UDESC, com 65,7\% e 64,4\%, respectivamente. No entanto, todas as instituições que estão integradas à ACAFE apresentam uma similaridade superior a 50\% com o Currículo Mundial. Em números absolutos, a UNIPLAC lidera com 41 disciplinas, seguida pela FURB e UNISUL com 34 disciplinas cada. Já entre as que possuem menos disciplinas similares destacam-se a UNIVILLE e a UDESC, com 23 cada.

Comparando estes resultados com os do estudo de Segantini et al. (2013), em que o índice de disciplinas semelhantes foi de 76,71\%, percebe-se que, em média $(75,7 \%)$, as instituições da ACAFE apresentam percentual semelhante às instituições do Mercosul, o que demonstra uma convergência na administração acadêmica das Instituições. No entanto, é importante destacar que na pesquisa de Czesnat, Cunha e Domingues (2009) com universidades de Santa Catarina o índice de similaridade 
foi de $88 \%$, o que indica uma diminuição na similaridade de disciplinas com a proposta da ONU/UNCTAD/ISAR. Considerando que esses autores analisaram 11 universidades contra 16 do estudo atual, pressupõe-se que pode haver oferta de disciplinas diferenciadas por regiões nas IES filiadas à ACAFE, levando à diminuição do índice de similaridade (de 2009 para 2015).

Com relação às disciplinas que não fazem parte daquelas sugeridas pelo Currículo Mundial, a maioria está ligada à Metodologia Científica, Orientação para Trabalhos de Conclusão de Curso, Produção de Textos e Sociologia. Um fato que pode interferir na avaliação entre as diferentes IES são as diferentes durações dos cursos, que variam entre 8 e 10 semestres, influindo na proporção final. Outro ponto a se destacar é a quantidade de disciplinas optativas oferecidas. A disparidade entre as IES pode induzir a conclusões imprecisas, pois algumas disciplinas que são optativas constam na matriz curricular sugerida pela ONU/UNCTAD/ISAR. Em geral, os números mostram uma convergência para seguir as normas internacionais nas disciplinas ofertadas pelas IES, porém, alguns temas ainda não são bem explorados.

Na Tabela 2 estão os percentuais dos blocos de conhecimento com maior quantidade de disciplinas similares em relação ao total de disciplinas do Currículo Mundial.

Tabela 2 - Similaridade entre Blocos de Conhecimentos e as disciplinas das universidades pesquisadas

\begin{tabular}{l|c}
\multicolumn{1}{c}{ Blocos de conhecimento } & $\%$ \\
\hline Conhecimento Administrativo e Organizacional & 20,5 \\
Tecnologia da Informação & 0,4 \\
Conhecimentos Contábeis, Financeiros e assuntos afins & 49,0 \\
Conhecimento (avançado) em Contabilidade, Finanças e assuntos afins & 30,1 \\
\hline
\end{tabular}

Fonte: Dados da pesquisa.

De acordo com a Tabela 2, o estudo evidencia maior similaridade nas áreas de Conhecimentos Contábeis, Financeiros e assuntos afins (49\%) e Conhecimento (avançado) em Contabilidade, Finanças e assuntos afins (30,1\%) nas IES da ACAFE do que observado no estudo de Segantini et al. (2013) com quatro universidades do Mercosul, que nos mesmos blocos encontrou 35,71\% e 17,86\%. Assim, infere-se que as matrizes curriculares das IES da ACAFE estão mais voltadas a assuntos na área contábil do que em conhecimentos administrativos. Encontrou-se um total de $79,1 \%$ nos blocos de contabilidade e assuntos afins. O resultado foi relativamente semelhante ao estudo de Czesnat, Cunha e Domingues (2009), que encontraram nesses mesmos blocos $54,2 \%$ de similaridade. Vale mencionar que em relação às tecnologias, houve um regresso quanto à similaridade entre os blocos de conhecimentos.

Na Tabela 3 percebe-se que se trabalha mais as cadeiras de Economia, Administração e Métodos Quantitativos para Empresas, enquanto as menos trabalhadas são Marketing e Mercado Internacional. Este resultado pode indicar a valorização de uma visão holística dos estudos econômicos, uma busca por uma melhor compreensão do mundo. Também se nota a força dos processos administrativos na formação do contabilista, e algo importante nesse sentido, que são os estudos dos métodos quantitativos e estatísticos.

A USJ, FURB e UNIBAVE podem ser destacadas positivamente por contemplarem maior número de disciplinas ofertadas. É interessante notar a pouca importância dada a disciplinas voltadas para quem empreende, como o Marketing, ou não considerar a Globalização e os Mercados Internacionais como assuntos vitais para o acadêmico de Contabilidade. 
Tabela 3 - Áreas de Conhecimento mais frequentes no Bloco Conhecimento Administrativo e Organizacional.

\begin{tabular}{|c|c|c|c|c|c|c|c|c|c|c|c|c|c|c|c|c|c|c|}
\hline Subáreas & 点 & $\stackrel{\overrightarrow{0}}{\stackrel{0}{U}}$ & 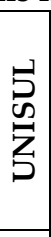 & $\begin{array}{l}U \\
\text { N } \\
\text { T1 } \\
\mathbf{Z} \\
\vdots\end{array}$ & 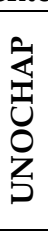 & 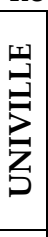 & $\sqrt[\omega]{\sigma}$ & 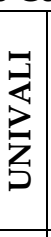 & 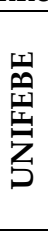 & $\begin{array}{c}\cup \\
\mathscr{N} \\
\text { 王 } \\
\supset\end{array}$ & $\begin{array}{l}\cup \\
\text { Z }\end{array}$ & $\begin{array}{l}u \\
w \\
\text { Z } \\
⿱ 亠 乂\end{array}$ & 总 & 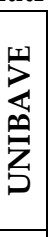 & 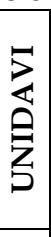 & 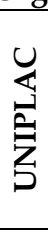 & تే & 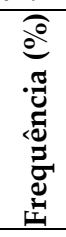 \\
\hline 1.1Economia & 2 & 1 & 3 & 1 & 1 & 1 & 2 & 1 & 1 & 1 & 1 & 1 & 1 & 1 & 1 & 1 & 20 & 19,6 \\
\hline $\begin{array}{l}1.2 \text { Métodos quantitativos e es- } \\
\text { tatísticos para as empresas }\end{array}$ & 3 & 2 & 3 & 2 & 2 & 2 & 2 & 1 & 2 & 3 & 2 & 2 & 2 & 2 & 1 & 2 & 33 & 32,4 \\
\hline $\begin{array}{l}\text { 1.3 Políticas empresariais, de } \\
\text { estruturas organizacionais bá- } \\
\text { sicas, e comportamento organi- } \\
\text { zacional }\end{array}$ & 1 & 3 & 0 & 3 & 2 & 1 & 4 & 1 & 3 & 3 & 3 & 2 & 3 & 2 & 3 & 2 & 36 & 35,3 \\
\hline $\begin{array}{l}1.4 \text { Funções e práticas adminis- } \\
\text { trativas, e gestão de operações }\end{array}$ & 1 & 0 & 0 & 0 & 0 & 1 & 1 & 2 & 0 & 0 & 0 & 0 & 0 & 1 & 0 & 0 & 6 & 5,9 \\
\hline 1.5 Marketing & 1 & 0 & 0 & 0 & 0 & 0 & 0 & 0 & 1 & 0 & 0 & 0 & 0 & 0 & 1 & 1 & 4 & 3,9 \\
\hline 1.6 Mercados internacionais & 0 & 0 & 0 & 0 & 0 & 0 & 0 & 0 & 0 & 0 & 0 & 0 & 0 & 2 & 0 & 1 & 3 & 2,9 \\
\hline Total & 8 & 6 & 6 & 6 & 5 & 5 & 9 & 5 & 7 & 7 & 6 & 5 & 6 & 8 & 6 & 7 & 102 & 100 \\
\hline
\end{tabular}

Fonte: Dados da pesquisa.

O presente estudo vai ao encontro do evidenciado por Czesnat, Cunha e Domingues (2009) e Segantini et al. (2013), de que métodos quantitativos e estatísticos para as empresas são as que mais estão presentes nas instituições. No entanto, como evidencia o presente estudo, políticas empresariais, de estruturas organizacionais básicas e comportamento estão com maior aplicação nas instituições da ACAFE. Na Tabela 4 fica nítido que a maioria das instituições não trabalha a Tecnologia de Informações.

Tabela 4 - Áreas de Conhecimento mais frequentes no Bloco Tecnologia de Informação.

\begin{tabular}{|c|c|c|c|c|c|c|c|c|c|c|c|c|c|c|c|c|c|}
\hline & 党 & $\stackrel{\overrightarrow{0}}{\stackrel{U}{U}}$ & 占 & $\begin{array}{l}\text { U } \\
\text { ñ1 } \\
0 \\
Z \\
\text { Z }\end{array}$ & $\begin{array}{l}\text { 岁 } \\
\text { I } \\
\text { ○ } \\
\text { Z }\end{array}$ & 罗 & 吕 & 尝 & 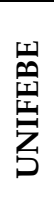 & 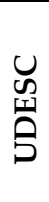 & 己 & \begin{tabular}{l} 
U \\
畀 \\
\multicolumn{2}{c}{}
\end{tabular} & $\begin{array}{l}\stackrel{a}{\Xi} \\
\text { 艺 }\end{array}$ & 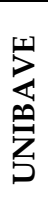 & 蛋 & 岁 & 完 \\
\hline 2.1 Tecnologia de informação & 0 & 0 & 0 & 0 & 0 & 0 & 1 & 0 & 0 & 0 & 0 & 0 & 0 & 1 & 0 & 0 & 2 \\
\hline Total & 0 & 0 & 0 & 0 & 0 & 0 & 1 & 0 & 0 & 0 & 0 & 0 & 0 & 1 & 0 & 0 & 2 \\
\hline
\end{tabular}

Fonte: dados da pesquisa.

Pode-se especular que esta área de conhecimento seja tratada em disciplinas de Contabilidade e de Custos que usem esta ferramenta. Ou seja, em vez de ser um tema em si, considera-se mais como apoio a outros campos do conhecimento. Os resultados são bem próximos (1,7\%) aos obtidos por Segantini et al. (2013), mas com uma distância visível ao achado de Czesnat, Cunha e Domingues (2009), que chegaram a 4,65\%, o que pode indicar que o tema é tratado em outras disciplinas pelas atuais instituições da ACAFE. Já na Tabela 5, que apresenta a área de Conhecimentos Contábeis, Financeiros e assuntos afins, a distribuição de disciplinas é mais equilibrada, distribuídas basicamente por todos os temas e IES.

Os destaques são a UNIPLAC e a FURB, com 22 e 17 disciplinas similares ao Currículo Mundial, respectivamente. A menor similaridade é a da UNIARP, com 13 disciplinas. A exceção entre os temas trabalhados são os Módulos Integrados Capstone. O que pode ter ocasionado esta frequência maior entre as instituições estudadas e o Currículo Mundial seria de que as disciplinas expostas na Tabela 5 tenham uma essência fundamental no curso e formação de bacharéis de Ciências Contábeis, podendo desta forma, explicar os resultados. 
Tabela 5 - Áreas de Conhecimento mais frequentes no Bloco Conhecimento Contábeis, Financeiros e Assuntos Afins.

\begin{tabular}{|c|c|c|c|c|c|c|c|c|c|c|c|c|c|c|c|c|c|c|}
\hline Subáreas & 点 & $\begin{array}{l}\overrightarrow{0} \\
\stackrel{u}{u}\end{array}$ & $\begin{array}{l}\text { 号 } \\
\text { 点 }\end{array}$ & $\begin{array}{l}u \\
\text { N } \\
01 \\
\vdots \\
Z\end{array}$ & 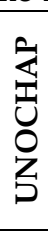 & $\begin{array}{l}\text { 岁 } \\
\text { 当 } \\
\text { 号 }\end{array}$ & $\stackrel{5}{n}$ & 壱 & $\begin{array}{l}\text { 崶 } \\
\text { 至 } \\
\text { 号 }\end{array}$ & 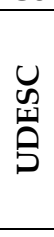 & Z & \begin{tabular}{l}
$u$ \\
D \\
$Z$ \\
\multicolumn{1}{|c}{}
\end{tabular} & $\begin{array}{l}\text { 采 } \\
\text { 岁 }\end{array}$ & 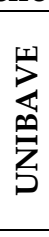 & 㕛 & 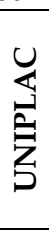 & $\underset{\tilde{0}}{\tilde{0}}$ & 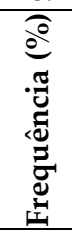 \\
\hline 3.1 Contabilidade básica; & 2 & 2 & 2 & 2 & 2 & 2 & 3 & 2 & 3 & 2 & 3 & 2 & 1 & 2 & 2 & 3 & 35 & 14,3 \\
\hline 3.2 Contabilidade financeira; & 2 & 2 & 2 & 2 & 2 & 2 & 1 & 2 & 3 & 3 & 2 & 3 & 2 & 2 & 2 & 3 & 35 & 14,3 \\
\hline $\begin{array}{l}\text { 3.3 Contabilidade financeira } \\
\text { avançada; }\end{array}$ & 1 & 2 & 2 & 2 & 2 & 1 & 1 & 2 & 2 & 1 & 1 & 2 & 3 & 1 & 2 & 2 & 27 & 11,1 \\
\hline $\begin{array}{l}\text { 3.4 Contabilidade gerencial - } \\
\text { conceitos básicos; }\end{array}$ & 2 & 1 & 2 & 2 & 2 & 2 & 1 & 1 & 2 & 2 & 2 & 2 & 2 & 2 & 2 & 2 & 29 & 11,9 \\
\hline 3.5 Tributação; & 2 & 1 & 2 & 2 & 1 & 2 & 0 & 2 & 2 & 2 & 1 & 2 & 2 & 2 & 2 & 4 & 29 & 11,9 \\
\hline $\begin{array}{l}3.6 \text { Sistemas de informações con- } \\
\text { tábeis; }\end{array}$ & 2 & 0 & 0 & 1 & 0 & 0 & 1 & 1 & 0 & 1 & 0 & 0 & 0 & 1 & 0 & 1 & 8 & 3,3 \\
\hline $\begin{array}{l}\text { 3.7 Direito comercial e empresa- } \\
\text { rial; }\end{array}$ & 2 & 2 & 2 & 2 & 2 & 2 & 2 & 2 & 1 & 2 & 1 & 2 & 0 & 2 & 2 & 4 & 30 & 12,3 \\
\hline $\begin{array}{l}3.8 \text { Fundamentos sobre audito- } \\
\text { ria; }\end{array}$ & 1 & 1 & 1 & 1 & 1 & 1 & 1 & 1 & 1 & 1 & 2 & 1 & 1 & 1 & 2 & 0 & 17 & 7 \\
\hline $\begin{array}{l}\text { 3.9 Finanças empresariais e ges- } \\
\text { tão financeira; }\end{array}$ & 3 & 2 & 2 & 2 & 3 & 1 & 2 & 2 & 2 & 2 & 2 & 2 & 0 & 2 & 2 & 3 & 32 & 13,1 \\
\hline $\begin{array}{l}3.10 \text { Módulo sobre integração do } \\
\text { conhecimento: } \text { a capstone }\end{array}$ & 0 & 0 & 0 & 0 & 0 & 0 & 0 & 0 & 0 & 0 & 0 & 0 & 2 & 0 & 0 & 0 & 2 & 0,8 \\
\hline Total & 17 & 13 & 15 & 16 & 15 & 13 & 12 & 15 & 16 & 16 & 14 & 16 & 13 & 15 & 16 & 22 & 244 & 100 \\
\hline
\end{tabular}

Fonte: Dados da pesquisa.

Czesnat, Cunha e Domingues (2009) constataram que 9 das 11 instituições pesquisadas contemplavam disciplinas do bloco de conhecimentos contábeis, financeiros e assuntos afins. O mesmo foi observado no estudo de Segantini et al. (2013). De acordo com autores citados, a maior similaridade observada nessa área do conhecimento está relacionada à importância de tais disciplinas nos cursos de Ciências Contábeis, que independem das regiões em que se ministra o curso, sendo essenciais para a formação de bacharéis em Ciências Contábeis.

Por fim, na Tabela 6 apresenta-se a similaridade de disciplinas mais avançadas, em que também se encontram quantidades equilibradas. As maiores disparidades estão nos estágios, sendo que algumas IES incentivam esta prática e outras não possuem esta disciplina.

Tabela 6 - Áreas de Conhecimento no Bloco Conhecimento (Avançado) em Contabilidade, Finanças e Assuntos Afins.

\begin{tabular}{|c|c|c|c|c|c|c|c|c|c|c|c|c|c|c|c|c|c|c|}
\hline Subáreas & 爷 & $\stackrel{\overrightarrow{0}}{\stackrel{4}{u}}$ & 岂 & 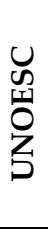 & 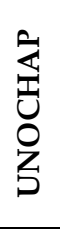 & 岂 & $\sqrt{\sigma}$ & 宓 & 䆓 & 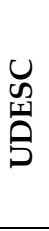 & Z & $\begin{array}{l}u \\
\text { 至 } \\
\vdots\end{array}$ & 恴 & 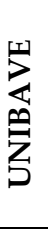 & 总 & 岁 & స్ㅠㅁ & 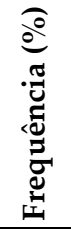 \\
\hline $\begin{array}{l}\text { 4.1 Demonstrações finan- } \\
\text { ceiras avançadas e Conta- } \\
\text { bilidade industrial; }\end{array}$ & 1 & 1 & 2 & 2 & 2 & 1 & 1 & 1 & 1 & 2 & 1 & 2 & 2 & 1 & 2 & 1 & 23 & 15,3 \\
\hline $\begin{array}{l}\text { 4.2 Contabilidade geren- } \\
\text { cial avançada; }\end{array}$ & 2 & 2 & 2 & 3 & 2 & 1 & 2 & 2 & 2 & 1 & 1 & 3 & 2 & 2 & 1 & 2 & 30 & 20 \\
\hline 4.3 Tributação avançada; & 1 & 3 & 1 & 1 & 1 & 1 & 1 & 2 & 2 & 1 & 2 & 3 & 2 & 0 & 3 & 1 & 25 & 16,8 \\
\hline $\begin{array}{l}\text { 4.4 Direito empresarial } \\
\text { avançado; }\end{array}$ & 2 & 2 & 2 & 1 & 2 & 2 & 2 & 3 & 1 & 1 & 2 & 0 & 2 & 1 & 2 & 1 & 26 & 17,3 \\
\hline $\begin{array}{l}\text { 4.5 Auditoria avançada; } \\
\text { 4.6 Finanças empresariais }\end{array}$ & 3 & 2 & 0 & 2 & 2 & 1 & 2 & 2 & 2 & 1 & 1 & 1 & 1 & 2 & 1 & 3 & 26 & 17,3 \\
\hline $\begin{array}{l}\text { avançadas e Administra- } \\
\text { ção financeira; }\end{array}$ & 4 & 0 & 0 & 0 & 3 & 0 & 0 & 0 & 0 & 0 & 3 & 4 & 1 & 0 & 1 & 4 & 20 & 13,3 \\
\hline Total & 13 & 10 & 7 & 9 & 12 & 6 & 8 & 10 & 8 & 6 & 10 & 13 & 10 & 6 & 10 & 12 & 150 & 100 \\
\hline
\end{tabular}

Fonte: Dados da pesquisa. 
Na Tabela 6 também se observa maior similaridade das disciplinas das instituições com o Currículo Mundial. Desta maneira, evidencia-se que as disciplinas primordiais são as mais equivalentes nas instituições, o que confirma a adoção por parte das IES investigadas de um modelo misto, pois as instituições se baseiam no Currículo Mundial para a base de conteúdo específico, independente da região em que a instituição está inserida. No entanto, as demais disciplinas são flexíveis, sendo reguladas pelas próprias instituições de ensino.

\section{CONSIDERAÇÕES FINAIS}

O estudo teve o objetivo comparar a adequação das matrizes curriculares dos cursos de Ciências Contábeis com a matriz curricular proposta pela ONU/UNCTAD/ISAR. Para tal, adotou-se uma pesquisa descritiva, com análise documental a partir de dados provenientes das matrizes curriculares das instituições de ensino filiadas à ACAFE. A abordagem foi qualitativa, com a utilização de análise conteúdo para responder à questão de pesquisa. Como resultado, constatou-se que 7 das 16 instituições que fazem parte do Sistema ACAFE apresentam média de similaridade das disciplinas de sua matriz curricular acima da média geral em relação ao currículo mundial. Desta forma, conclui-se que estas instituições estão mais próximas de uma congruência de seu currículo com o proposto pela ONU/UNCTAD/ISAR.

Destaca-se um crescimento nas áreas de Conhecimentos Contábeis, Financeiros e assuntos afins e Conhecimento (avançado) em Contabilidade, Finanças e assuntos afins. As subáreas de políticas empresariais, de estruturas organizacionais básicas e comportamento estão sendo as mais abordadas nas instituições da ACAFE. Os métodos quantitativos e estatísticos são os que mais estão presentes nas matrizes curriculares das instituições. Contatou-se também um aumento nas subáreas de finanças empresariais e gestão financeira e módulo sobre integração do conhecimento.

A contribuição do estudo consistiu em identificar os conteúdos abordados nos cursos de graduação em ciências contábeis das IES do Sistema ACAFE e observar o nível de similaridade das estruturas curriculares em relação ao currículo mundial.

Como limitação à pesquisa, destaca-se que as matrizes curriculares não possuem uniformidade na sua estrutura e, desta forma, a análise das disciplinas e seu alinhamento ao currículo mundial pode ter sido prejudicada, pelas diferentes nomenclaturas adotadas. Outra limitação do estudo foi o fato de não se analisar as ementas das disciplinas optativas, que podem ou não estar alinhadas com os conteúdos sugeridos pela ONU/UNCTAD/ISAR.

Como sugestão de estudos futuros, os números mostram uma convergência para seguir as normas internacionais nas disciplinas ofertadas pelas IES. No entanto, pode ser oportuno avaliar as ementas dessas disciplinas, para verificar se estas estão alinhadas com as disciplinas sugeridas pelo Currículo Mundial.

\section{REFERÊNCIAS}

CAVALCANTE, D. S. et al. Adequação dos currículos dos cursos de Contabilidade das universidades federais brasileiras ao currículo mundial de contabilidade e o desempenho no ENADE. Pensar Contábil, v. 13, n. 50, 2011.

CAVALCANTI, L. T. Análise sobre o nível de similaridade dos currículos dos cursos de Ciências Contábeis das instituições de ensino superior do estado de Goiás em relação ao currículo mundial proposto pelo ISAR/UNCTAD/ONU. 2013. 73 f. Trabalho de Conclusão de Curso (Graduação) - Faculdade de Administração, Ciências Contábeis e Economia, Universidade Federal de Goiás, Goiânia, 2013. 
CZESNAT, A. O.; DA CUNHA, J. V. A.; DOMINGUES, M. J. C. S. Análise comparativa entre os currículos dos cursos de ciências contábeis das universidades do estado de santa Catarina listadas pelo MEC e o currículo mundial proposto pela ONU/UNCTAD/ISAR. Gestão \& Regionalidade (Online), v. 25, n. 75, 2009.

ERFURTH, A. E.; DOMINGUES, M. J. C. S. Estrutura curricular do curso de ciências contábeis na universidade de Buenos Aires versus a estrutura curricular proposta pelo ISAR/UNCTAD. Seminário de Ciências Contábeis FURB, v. 4, 2008.

ERFURTH, A. E.; DOMINGUES, M. J. C. S. Currículo Mundial e o Ensino de Contabilidade: Estudo dos Cursos de Graduação em Ciências Contábeis em Instituições de Ensino Superior Brasileiras e Argentinas. ConTexto, v. 13, n. 23, p. 47-60, 2011.

KLANN, R. C. et al. Avaliação de desempenho das instituições de ensino superior pertencentes à Associação Catarinense das Fundações Educacionais (ACAFE). Contabilidade, Gestão e Governança, v. 15, n. 3, 2012.

LEMES, S.; DE CARVALHO, L. N. G. Comparabilidade entre o resultado em BR GAAP e US GAAP: evidências das companhias brasileiras listadas nas bolsas norte-americanas. Revista Contabilidade E Finanças, v. 20, n. 50, p. 25-45, 2009.

MAGALHÃES, F. A. C.; ANDRADE, J. X. A educação contábil no estado do Piauí diante da proposta de convergência internacional do currículo de contabilidade concebida pela ONU/UNCTAD/ISAR. In: Congresso USP de Controladoria e Contabilidade. 2006.

NEZ, E. et al. Ranking das Instituições de Ensino Superior do Sistema ACAFE a Partir dos Indicadores de Desempenho Econômico, Financeiro e de Atividades. Pensar Contábil, v. 16, n. 60, 2014.

NIYAMA, J. K. Contabilidade internacional: causas das diferenças internacionais, harmonização contábil internacional, estudo comparativo entre países, divergências nos critérios de reconhecimento e mensuração, evidenciação segundo FASB e IASB. São Paulo: Atlas, 2005.

RICCIO, E. L.; SAKATA, M. C. G. Evidências da globalização na educação contábil: estudo das grades curriculares dos cursos de graduação em universidades brasileiras e portuguesas. Revista Contabilidade E Finanças, v. 15, n. 35, p. 35-44, 2004.

SANTOS, A. C.; DOMINGUES, M. J. C. S.; RIBEIRO, M. J. Nível de similaridade das matrizes curriculares dos cursos de ciências contábeis das instituições paranaenses listadas no mec., ao currículo mundial. Registro Contábil, v. 4, n. 3, p. 105-127, 2013.

SEGANTINI, Giovanna Tonetto et al. Uma Análise Crítica Entre os Currículos dos Cursos de Ciências Contábeis nos Países do Mercosul e o Proposto Pela ONU/UNCTAD/ISAR. Revista Evidenciação Contábil \& Finanças, v. 1, n. 1, p. 85-98, 2013.

UNCTAD/ISAR. TD/B/COM.2/ISAR/5 - Directiva para a elaboración de un programa mundial de estúdios de Contabilidad y otras normas y requisitos de cualificación. Gienebra, 1999a. 2009 
UNCTAD/ISAR. TD/B/COM.2/ISAR/6 - Plan de studios mundial para la formación de constables professionals. Gienebra, 1999b. 2009

UNCTAD/ISAR. TD/B/COM.2/ISAR/21 -Plan de studios mundial para la formación de constables professionals (revisado). Gienebra, 2003. 2009

UNCTAD/ISAR. TD/B/COM.2/ISAR/21 - Revised model accounting curriculum (CM). 2003. Disponível em: <http://unctad.org/en/docs/c2isar21_en.pdf>. Acesso em: 15 jul. 2016. 